\title{
A new coupling process for synthesis of epichlorohydrin from dichloropropanols
}

\author{
Dawei Wu, Sumin Zhou* \\ School of Chemical Engineering, Huaiyin Institute of Technology, Huaian 223005, China \\ ccsm@hyit.edu.cn
}

Keywords: dichloropropanol, epichlorohydrin, tubular reactor, wiped film evaporation.

\begin{abstract}
As an important material used in the production of epoxy resins, epichlorohydrin is usually derived from the saponification and cyclization of dichloropropanol in a tower reacting system. In order to reduce energy consumption and wastewater discharge, a new process of tubular reactor coupled with wiped film evaporation was adopt to produce epichlorohydrin. The effects of different technological parameters on the yield of the coupling process were investigated, such as reactants' molar ratio, reaction \& evaporation temperature, residence time and so on. Results indicated that the use of coupling process will significantly reduce the material consumption and shorter the reaction time. This coupling process provided a useful suggestion for the design of the industrial plants.
\end{abstract}

\section{Introduction}

Epichlorohydyin (ECH), also known as 1-chloro-2, 3-epoxy propane, is an important chemical material, mainly used to synthesizing epoxy resin, chlorohydrins rubber, pesticide, plasticizer and so on [1]. The main method to produce ECH is high-temperature chlorination of propylene [2]. With the fast-development of biodiesel production, the use of glycerol for producing ECH [3-4] is going to mature and has become an important industrial technological process [5]. Although the difference raw materials were used, the processes also consist of two reaction steps as well. First step is the saponification and cyclization of dichloropropanol (DCP) to produce ECH. Second step is the separation and purification of ECH. In the second step, the side reactions is very easy to occur because the chemical activeness of $\mathrm{ECH}$, and turned to be the 1-chloro-epoxy propane or glycerin which result in reducing the yield of ECH (formula 1) [6-7]. In the industrial production, the use of tower reactor in which reaction and dehydration were combined to maintain a shorter reaction time, meanwhile the continuous and stable production of ECH is coming true [8]. Unfortunately, this combine process still has several deficiencies such as the complicated operation procedure, higher energy consumption, more wastewater discharge, longer tubular residence time and lower product yield.

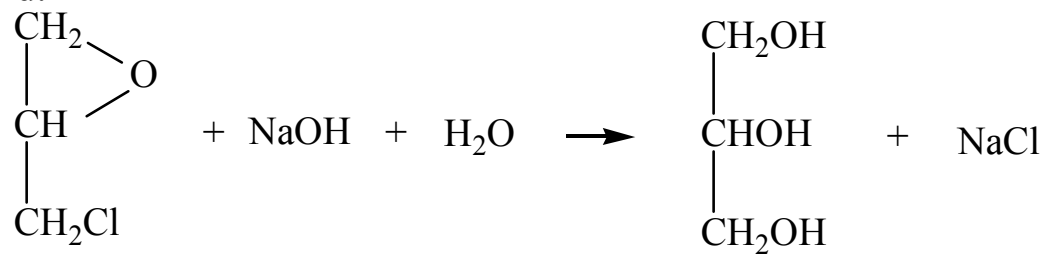

To reduce the deficiency of the towerreacting system, Zhang et. al[9] suggested a dichloropropanol saponification process in metal tubular reactor, the production yield reached 95.2\% under the optimal conditions. Yan et.al. [10] Studied the new process of synthesizing ECH continuously in micro-tubular reactor and the yield of epichlorohydrin reached 98.5\%. Que et. al. [11] use tubular reactor coupled with reaction distillation process, the yield of epichlorohydrin was attained $95-96 \%$. Compared with traditional towerreacting technology, the coupling process of tubular reactor-rectification shows its improvement such as simple operation process, lower energy consumption, less wastewater discharge, accurate tubular residence time controlling, and the raw material consumption is expected to further reduce. 
This paper suggested a novel process of tubular reactor coupling with wiped film evaporation (WFE) to produce epichlorohydrin. The technological parameters of the coupling process were discussed.WFE is a kind of quick separating technology used to cope with high activity products. It's widely used in chemical and pharmaceutical industries, foods industries, environmental protection and other industries [11,12]. This technology has lots of advantages such as large evaporation area, higher evaporation rate, shorter residence time, flexible operating and so on. Till now, the use of WFE in ECH production has not been reported yet. This research will provide a useful method for the application of the industrial plants.

\section{Experimental}

\subsection{Materials}

Different mass fraction of Sodium hydroxide solution was prepared. dichloropropanol (DCP) was synthesized via glycerinum and hydrogen chloride at $110-120^{\circ} \mathrm{C}$. The product was purified by vacuum distillation.

\subsection{Experiment Procedure}

The coupling process of tubular reactor with WFP shows in fig.1. The solution of DCP and $\mathrm{NaOH}$ were metered and pumped into heat exchanger, then pumped into tubular reactor by respectively. Product mixtures were distilled in the WFP. The mixture of ECH and water was steamed out from the WFP then introduced into a condenser in which been cooled in to liquid. The oil phase of liquid was separated by a separator to obtain the azeotrope of $\mathrm{ECH}$.

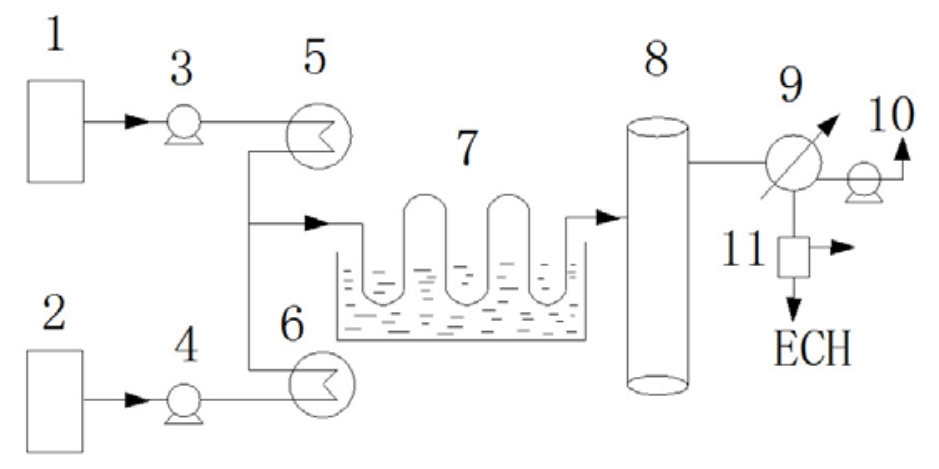

Fig.1 Process flow diagram of coupling process

1- $\mathrm{NaOH}$ tank, 2-DCP tank, 3,4-supply pump, 5,6-preheater,

7-tubular reactor, 8-WFP, 9-condenser, 10-vacuum pump, 11- separator

The yield of ECH was defined as: $\quad \mathrm{Y}=\frac{1.39 \mathrm{~m}_{\mathrm{O}}(1-\mathrm{A}) \mathrm{X}}{\mathrm{m}_{\mathrm{dcp}}}$

Where the $\mathrm{m}_{\mathrm{O}}$ is the mass of oil phase in azeotrope, $\mathrm{A}$ is moisture content, $\mathrm{X}$ is the mass of the oil phase after dehydration, $\mathrm{m}_{\mathrm{DCP}}$ is the mass of the consumption of DCP.

\section{Results and Discussion}

\subsection{Effect of tubular reaction temperature}

The tubular residence time was maintained at 10s, and $n(D C P): n(N a O H)=1.05: 1$. the fraction of $\mathrm{NaOH}$ solution was $20 \%$ ( wt. \%). The evaporating temperature of wiped film was $45^{\circ} \mathrm{C}$, and the evaporating pressure of wiped film was $0.1 \mathrm{MPa}$. The influence of reaction temperature $\left(40 \sim 60^{\circ} \mathrm{C}\right)$ on yield was showed in fig. 2 . 


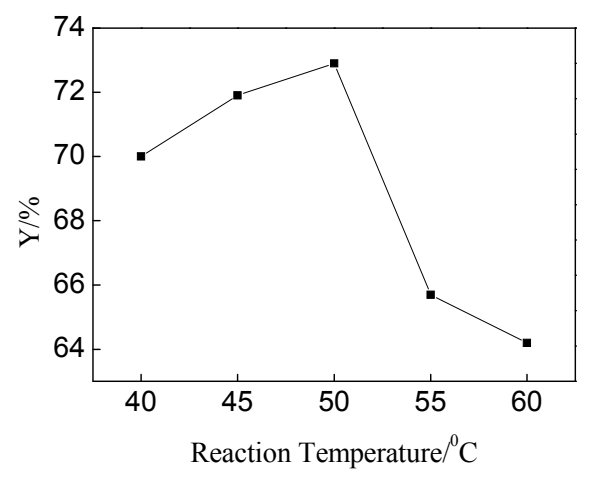

Fig.2 Effect of tubular reaction temperature on ECH yield of the coupling process

It could be seen from figure 2 that the yield of ECH increased gradually and then declined rapidly with the rise of reaction temperature. It reached the maximum value of $73.8 \%$ when the temperature was $50^{\circ} \mathrm{C}$. This is mainly because the reaction rate is the main factor influenced the yield when temperature is less than $50^{\circ} \mathrm{C}$. With the rise of reaction temperature, the molecular activation energy increased in the reaction system, and reaction rate was accelerated, conversion rate increased, and the yield increased. When the temperature was reached $50^{\circ} \mathrm{C}$, the raw material was completely converted, and afterward the side reaction of ECH became the main factor influencing the yield. With the continuous rise of reaction temperature, the side reaction rate of hydrolyzing was accelerated, and the hydrolysis reaction of ECH was took the control of system which caused the rapid reduce of yield.

The result of these experiments suggested that the optima tubular reaction temperature is $50^{\circ} \mathrm{C}$.

\subsection{Effect of residence time in tubular reactor on yield}

The temperature of tubular reaction was controlled at $50{ }^{\circ} \mathrm{C}$, and the other conditions were unchanged. The residence time in tubular reactor was changed from $5 \mathrm{~s}$ to $25 \mathrm{~s}$. ECH yield was recorded displayed in fig. 3 .

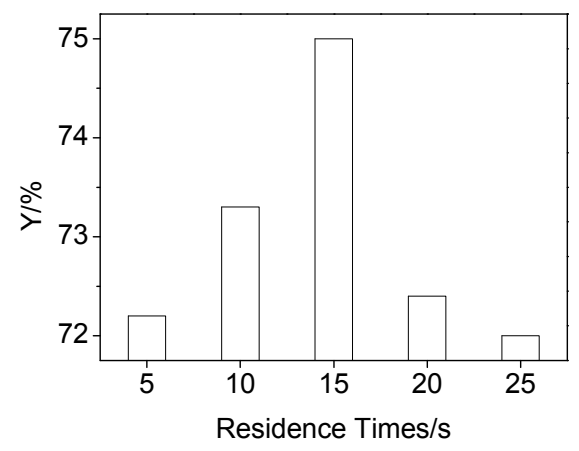

Fig.3 Effect of residence time on ECH yield

The yield of ECH first increased with the rise of residence time from $5 \mathrm{~s}$ to $15 \mathrm{~s}$, and then declined with the extension of residence time. The highest value of yield was $90 \%$ when the time was $15 \mathrm{~s}$. It is mainly because the incomplete reaction of the system when the residence time is less than $15 \mathrm{~s}$. The extension of residence time could promote the conversion rate of raw material and the yield of ECH. After residence time is over $15 \mathrm{~s}$, side reaction of the system can be strengthened in the alkali environment. The decomposition rate of product is the main factor which influences the yield, thus the yield decline significantly. These experiments recommended that residence time should be controlled at about $15 \mathrm{~s}$.

\subsection{Effect of reactant ratio on coupling yield}

Set the residence time of tubular reaction at $15 \mathrm{~s}$, and the other conditions were remained unchanged. Influence of the ratio of $\mathrm{n}$ (Noah) : $\mathrm{n}$ (DCP) on the yield was investigated while it was changed from 1 to 1.1 . See the results in figure 4 . 


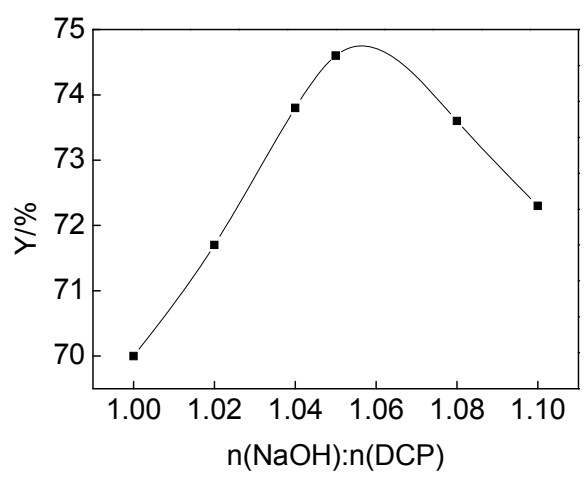

Fig.4 Effect of reactant molar ratio on ECH yield of the coupling process

It could be seen from figure 4 that the yield of ECH increased first, then declined with the rise of molar ratio of $\mathrm{n}$ (Noah): $\mathrm{n}$ (DCP). The maximum yield was acquired at value of 1.0:1.05 in which the yield was $74.6 \%$. Analysis of its causes according to the reaction mechanism could conclude that when $\mathrm{n}(\mathrm{NaOH}): \mathrm{n}(\mathrm{DCP})$ was close to 1.0 , the concentrations of DCP and $\mathrm{NaOH}$ of the system is decreasing gradually as the rapid reaction of the system. The probability of effective molecules collision is reduced rapidly. In addition, it's hard to make the conversion of raw material complete. Considering the above the yield of $\mathrm{ECH}$ is lower. But if the quantity of $\mathrm{NaOH}$ is excessive, it will cause increasing the probability of side reaction and reduce the yield, which is the reason of the yield decline after $\mathrm{n}(\mathrm{NaOH})$ : $\mathrm{n}(\mathrm{DCP})$ exceeded 1.05.

\subsection{Effect of evaporating temperature on coupling yield}

It should know that the mixture of product came out from the tubular reactor contained the whole reactants system which still has the abilities to generate chemical reaction. Therefore the research on the relationship between the evaporating temperatures and yields were very necessary.

While other conditions were kept constant, Change the thin film evaporating temperature from $35^{\circ} \mathrm{C}$ to $65^{\circ} \mathrm{C}$, the influence of the temperature on yield was investigated (fig.5)

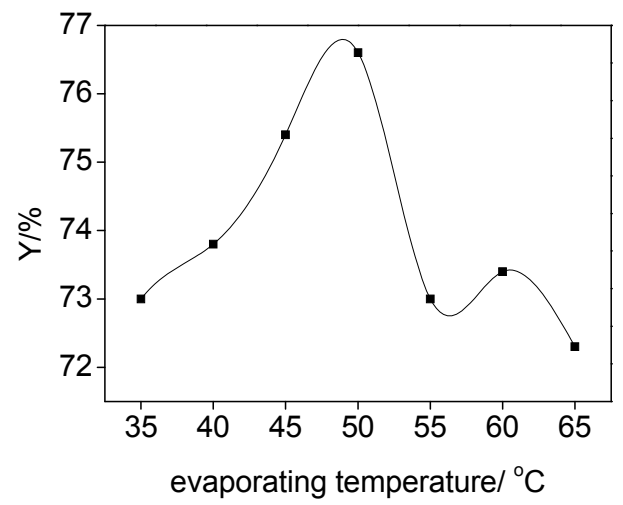

Fig.5 Effect of wiped film evaporating temperature on ECH yield of the coupling process

It can be seen from figure 5 that the yield of ECH increased first and then declined with the rise of the thin film evaporating temperature. Maximum yield was got at $50^{\circ} \mathrm{C}$, and the yield was $76.6 \%$. The yields were gone downward when the temperatures exceeded $50^{\circ} \mathrm{C}$.

The results displayed above could be explained as follow. Temperature and residence time are two combined factors of ECH hydrolyzing side reaction. On the one hand, the evaporation velocity of ECH products are separated slowly when the evaporation temperature maintained a lower level. It will also cause the longer residence time which lead to the longer side reaction time duration. Accumulation effect of decomposition reaction will be more significant. On the other hand, the lower temperature of WFE temperature slowed the side reaction rate of ECH decomposition. The balance of these two effects is to keep the evaporating temperature at $50^{\circ} \mathrm{C}$ according to the experiments. 


\subsection{Optimum conditions of coupling process}

According to the results of the investigation, the optimum conditions of coupling process of tubular reactor with WFP were showed on Table 1.

Table 1 Optimum conditions of coupling process

\begin{tabular}{cc}
\hline Technological parameter & Value \\
\hline Reaction temperature $/{ }^{\circ} \mathrm{C}$ & 50 \\
Residence time $/ \mathrm{s}$ & 15 \\
$\mathrm{n}(\mathrm{NaOH}): \mathrm{n}(\mathrm{DCP})$ & $1.05: 1$ \\
Alkali mass fraction $/ \%$ & 20 \\
Separation temperature $/{ }^{\circ} \mathrm{C}$ & 50 \\
\hline
\end{tabular}

Compared with other process, this coupling process reduced the reaction temperature, reaction time and the dosage of alkali. It can quick separate ECH from synthesized product and more flexible operation.

\section{Conclusion}

Tubular reactor coupled with WEF could be an innovative process to synthesize of epichlorohydrin. Under the optimized process conditions in this research, the $n(\mathrm{NaOH}): \mathrm{n}(\mathrm{DCP})$ was $1.05: 1, \mathrm{NaOH}$ solution mass fraction was $20 \%$, reaction temperature was $50{ }^{\circ} \mathrm{C}$, wiped film evaporation temperature at $50{ }^{\circ} \mathrm{C}$, tubular residence time was $15 \mathrm{~s}$, evaporating pressure of wiped film was $0.1 \mathrm{MPa}$, the yield of epichlorohydrin could reached $77.3 \%$.

The coupling process of tubular reaction with WFE shows its improvements on its lower material consumption, shorter reacting time and better operation flexibility, energy consumption and less wastewater discharge, compared with other processes. These advantages make possible of the industrial application.

\section{References}

[1] Chen,Z.M., the economy analysis of epichlorohydrin technology and market [J]. China Chlor-Alkali,2009,2:p.1-5.

[2] Dai,L.G.,Zhang,Y.Q.,Liu,Y.et al. The research progress of epichlorohydrin synthesis [J]. Petrochemical Technology,2008,37(7): p.738-743.

[3] Pagliaro M,Ciriminna R,Kimura H.From glycerol to value added products[J].Angewandte Chemie International Edition,2007,46(24): p.4434-4440.

[4] Bell B,Briggs J,Campbell R.Glycerin as a renewable feedstock for epichlorohydrin production:the GTE process[J].Clean-Soil,Air,Water,2008,36(8): p.657-661 .

[5] Avelino S,Sara I,Alexandra V.Chemical routes for the transformation of biomass into chemical[J].Chemical Review,2007,107( 6) : p.2411-2502.

[6] Santacesaria E,Tesser R,Di Serio M,et al.New process forproducing epichlorohydrin via glycerol chlorination[J]. Industrial \& Engineering Chemistry Research,2010,49( 3): p.964-970.

[7] Ma L,Zhu J W,Yuan X Q,et al.Synthesis of epichlorohydrin from dichloropropanols. Kinetic aspects of the process[J]. Chem. Eng. Res. Des.2007,85( A12): p.1580-1585.

[8] Eugeniusz M,Anna K,Agnieszka W,et al.The influence of technological parameters on dehydrochlorination of dichloropropanols[J].Industrial \& Engineering Chemistry Research,2012,51: p.3575-3579.

[9] Zhang,Y.,Li,J.S.,Yan,S.H.et al. the research of saponification cyclization of dichloropropanol in micro-tubular reactor system [J]. Modern Chemical Industry,2012,32(2): p.82-86.

[10] Yan,H.S.,Zhang,W.,Zhang,Y.et al. A new synthesis methods of epichlorohydrin in micro-tubular reactor [P].CN:102875494A,2013-01-16.

[11]Ma,B.Q.,Yuan,M.Q.,Chen,B.W., The synthesis process research of epichlorohydrin from dichloropropanols [J]. Chlor-Alkali Industry,2012,48(1): p.25-28. 
[12]Pi,P.H.,Yang,Z.R.,Ma,S.P., The characteristics and application of wiped film evaporator [J]. Modern Chemical Industry,2001,21( 3): p.41-44. 